\title{
PERFORMANCE ANALYSIS OF MULTI- FUNCTIONAL GRID CONNECTED CONVERTER UNDER DIFFERENT OPERATING MODES
}

\author{
Vinod Kumar Yadav', Dr. Rajnish Bhasker², Satyam Kumar Upadhyay² \\ ${ }^{1}$ M.Tech Scholar, Department of Electrical Engineering, \\ Veer Bahadur Singh Purvanchal University, Jaunpur, Uttar Pradesh, India \\ ${ }^{2}$ Assistant Professor, Department of Electrical Engineering, \\ Veer Bahadur Singh Purvanchal University, Jaunpur, Uttar Pradesh, India
}

\begin{abstract}
The increasing utilization of renewable energy sources (RESS) plays a vital role within the modern grid. The high penetration of the RESs within the electric power network results in challenges to the system's stability. This paper presents a multifunctional grid connected converter, controlled using current loop control. The multifunctional converter acts as an interface between various non-conventional sources and also the grid. The battery is employed to either supply or store power surges or transients. Multifunctional features of the converter includes active power injection, active power compensation, reactive compensation, harmonics compensation and other modes. The validity of the proposed model is verified within the real-time simulation of Typhoon HIL software.
\end{abstract}

Key words: AC micro grids, Renewable Energy Sources (RESs) Multifunctional converter Power quality, Hardware-in-the-loop simulation

Cite this Article: Vinod Kumar Yadav, Rajnish Bhasker, Satyam Kumar Upadhyay. Performance Analysis of Multi-functional Grid connected Converter Under different Operating Modes. International Journal of Electrical Engineering and Technology (IJEET). 12(9), 2021, pp. 91-106.

https://iaeme.com/Home/issue/IJEET?Volume=12\&Issue $=9$

\section{INTRODUCTION}

In renewable energy and storage applications that need high power density, the utilization of half-bridge converter is more preferable than the total bridge converter. Also, smart converters must be equipped with multiple functionalities [1-2]. Some advantages of this application are:

1. Converter are often operated in seven different modes using just one simple topology

2. All seven operating modes are embedded in one controller 
This application demonstrates seven possible modes of operation with control strategy supported conservative power theory [3-4]. The Bidirectional Multifunctional Converter is ready to work within the following modes:

- Active Power Injection

- Active Power Compensation

- Reactive Compensation

- Harmonic Compensation

- Active Power Injection and Reactive Compensation

- Active Power Consumption and Reactive Compensator

- Stand-by.

Distributed Generation (DG) is defined as electrical power generation with within the distribution networks or on the buyer side of the network. To utilize interfacing converters to compensate harmonics an enhanced current control approach is introduced in [1]. With inverter control, the active and reactive power requirement of the load may be satisfied [2]. Distributed generation (DG) units interfaced with static inverters are being applied and focused increasingly because of the very fact that conventional electrical power systems are being more and more stressed by expanding power demand, limit of power delivery capability, complications in building new transmission lines, and blackouts [5-9]. Power quality, safety and environmental concerns and commercial incentives are making energy sources [3] [4] popular. Various control techniques are presented in [10]. This paper deals with the modeling, simulation and harmonics and reactive power compensation of grid connected PV based distributed generation within the present study, the synchronous organization strategy is employed to get current reference for compensation and traditional PI controllers are used for control. The synchronous organization strategy utilizes co-ordinate transformations to separate the reactive and harmonic content within the load current. The control techniques proposed in [11] minimizes the amount of measurements and sensors.[12] presents the operation of grid connected DG system driven by dc-dc step-up converter and a dc-ac voltage source inverter and therefore the design, modeling and control of power converters for power quality improvement during a grid-connected DG system is presented in [13].The old-fashioned electricity generation scenario has been changing considering that almost all a part of its conventional generation ends up in pollutant processes, and consequently it causes risks and impacts to the environment and humans. The new generation scenario is been modified because it uses alternative and renewable voltage sources with the distributed generation (DG) concept next to the consumption centers, integrating sources like photovoltaic, wind, fuel cell, and other with the standard distribution utility grid [1e4]. In 2035, considering the population increasing and also the industrial sector expanding, mainly within the development country, the worldwide electricity consumption is estimated to be increased over 50\% compared to 2008 [5].

\subsection{Single Phase PLL}

The single phase PLL component has two operation modes, with enabled gain scheduling where P, I and D gains depend upon error and can vary between lower and better values. If the scheduling is disabled lower values of $\mathrm{P}, \mathrm{I}$ and $\mathrm{D}$ gains are going to be used. Single phase PLL component relies on Second Order Generalized integrator (SOGI). The second order generalized integrator has been widely accustomed implement grid synchronization for gridconnected converters. 


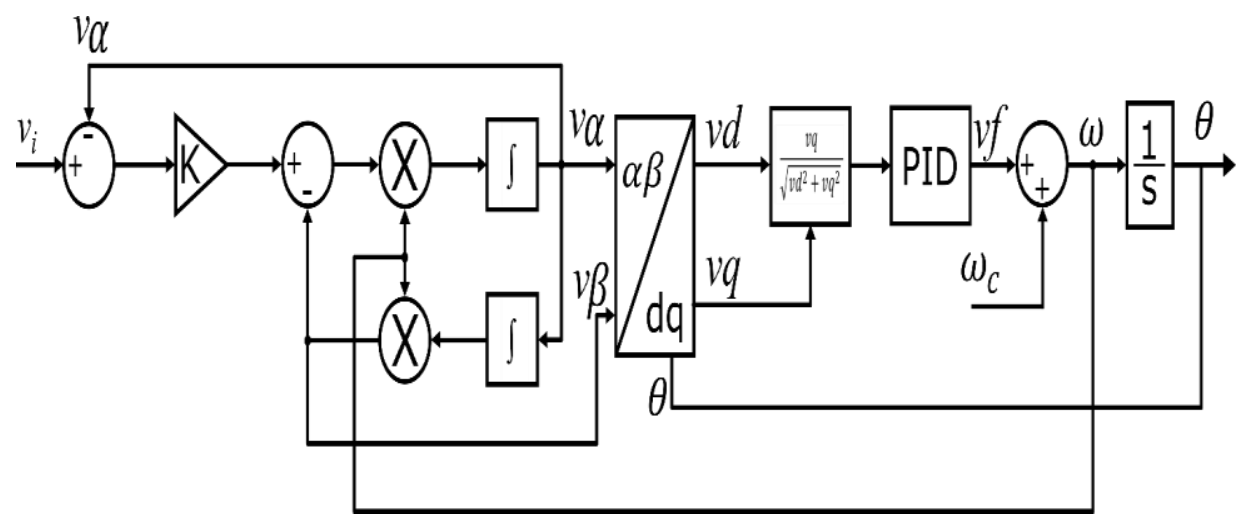

Figure 1 single phase PLL

The sinusoidal input value is represented by vi. $\mathrm{K}$ is that the damping factor of the SOGI algorithm. The $\alpha \beta$ signals, generated by SOGI algorithm are transformed into direct-quadrature frame through the Park transformation. The q-axis a part of the signal within the dq frame of reference, normalized with amplitude because the base value, represents the error signal which feeds the PID block. The goal of the PID is to stay q-axis part on the zero value, which captures whole sign in d-axis. Thus, d-axis value represents value synchronized with the sign.

\subsection{Discrete Transfer Function}

The discrete transfer function of a system is a discrete representation of the continuous system in the s-domain discretized according to the sampling time Ts The output $\mathrm{H}(\mathrm{z})$ of Discrete Transfer Function is calculated using following formula:

$$
H(z)=\frac{\operatorname{num}(z)}{\operatorname{den}(z)}=\frac{n u m_{0} z^{m}+n u m_{1} z^{m-1}+\cdots+n u m_{m}}{\operatorname{den}_{0} z^{n}+\operatorname{den}_{1} z^{n-1}+\cdots+\operatorname{den}_{n}}
$$

Where $m+1$ and $n+1$ are the number of numerator and denominator coefficients. Initial value of states of the transfer function are set to zero.

\section{CONSERVATIVE POWER THEORY}

Conservative Power Theory is the orthogonal decomposition of currents. It was proposed by Tenti et all [14] and is defined in the time domain. Conservative Power Theory can be used in single-phase and poly-phase systems with or without return conductor. This theory is based on instantaneous complex power that exists in non-sinusoidal conditions. Conservative power theory can be used for controlling power electronics processors such as active power filters. The instantaneous active and reactive power, as defined by the CPT authors are given by,

Instantaneous active power:

$$
p(t)=v \cdot i=\sum_{m=1}^{M} v_{m} i_{m}
$$

The average value of (2) is given by (3) as

$$
P=\frac{1}{T} \int_{0}^{T} v \cdot i d(t)
$$

Instantaneous reactive power:

$$
w(t)=\hat{v} \cdot i=\sum_{m=1}^{M} \hat{v}_{m} i_{m}
$$


The average value of (4) is given by (5) as

$$
W=\frac{1}{T} \int_{0}^{T} v \cdot i d(t)
$$

The load currents can be decomposed into active currents, reactive currents and void currents defined as,

Active Currents: Active current, which is responsible for active power, is given by (6)

$$
i_{a}(t)=\frac{\langle v(t), i(t)\rangle}{\|v\| 2} v(t)
$$

- Reactive Currents: Reactive current, which is responsible for reactive power, is given by (7)

$$
i_{r}(t)=\frac{\langle\hat{v}(t), i(t)\rangle}{\|v\| 2} \hat{v}(t)
$$

- Void Currents: The void current is then given by (8). It is responsible for the harmonics in the system occurring due to non-linear loads.

$$
i_{v}(t)=i(t)-i_{a}(t)-i_{r}(t)
$$

Based on the above definition, the current can be decomposed as:

$$
i(t)=i_{a}(t)+i_{r}(t)+i_{v}(t)
$$

By definition the three current components are orthogonal, thus:

$$
I^{2}=I_{a}^{2}+I_{r}^{2}+I_{v}^{2}
$$

This consideration is the basis of multi-functional methods, which make use of a power electronic converter connected directly in the utility grid across the measurement port, to injecting active power and/or compensation to the grid. In single-phase systems, there exists no balance or unbalance currents. However, when it comes to poly-phase systems, there may be an unbalance in currents in different phases due to load imbalance, varying impedances, etc. For such conditions, active currents and reactive currents can be further decomposed into balanced and unbalanced currents.

\section{ACTIVE POWER AND REACTIVE POWER AND HARMONIC COMPENSATION}

The filter connected to AC system has two objectives

1. To minimize the effect of harmonic voltage and current in the power system below an acceptable level.

2. To compensate the reactive power required by the loads. Two types of filters used for the above purposes which are

- Passive filter

- Active power filter

\subsection{Passive filter}

The passive filter requires resistors, inductors, and capacitors and they do not depend upon any type of external power source. By proper selection of $\mathrm{L}$ and $\mathrm{C}$, they are tuned to bypass a particular harmonic component. Multiple numbers of passive filters are connected in parallel to nullify higher order of harmonics as shown in Fig.1. Though passive filters were widely used as harmonic improvement and reactive power compensation devices in the power distribution system, their performances is not satisfactory due to following reasons:

- A separate filter is necessary for each harmonic frequency.

- Passive filter must be designed in considering with current provided by nonlinear load. 
- Source impedance affects the compensation characteristics of LC filters.

- When the content of harmonics in the AC line increases, the filter will be loaded.

- Frequency variation of AC source and tolerances in the filter components will affect the compensation characteristics of LC filters. If the system frequency varies in wide range, components required for attaining tuned frequency become impracticable.

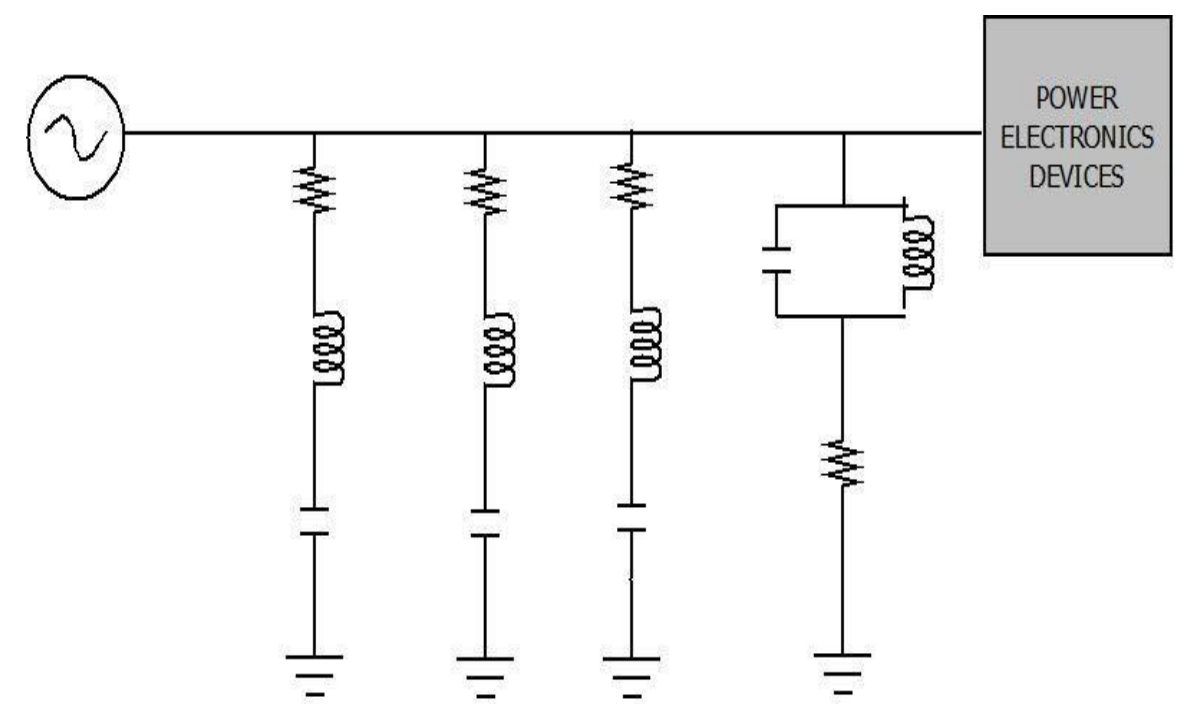

Figure 2 Block diagram for passive filter connected power system

\subsection{Active Power Filter}

Capacitors find frequently applications in active and passive filters for the mitigation of harmonics. With a view to safeguard the power system using the means of limiting harmonic currents to move into it by providing a low impedance path, passive filters are used. Passive filters are constituted with the help of capacitors, inductors and resistors. Special equipment employing power electronic converters to counteract current and voltage harmonics generated by nonlinear loads are nothing but active filters. They mostly find applications in distribution networks for sagging in voltage, flickering, where there are harmonics in current and voltages, etc. Using the filter would result into a better quality of power. Power quality problems are well improved with the flexibility and versatility of active filters to mitigate harmonic currents and voltage in the power system. The compensated voltage cancels out the voltage harmonics produced in the load.

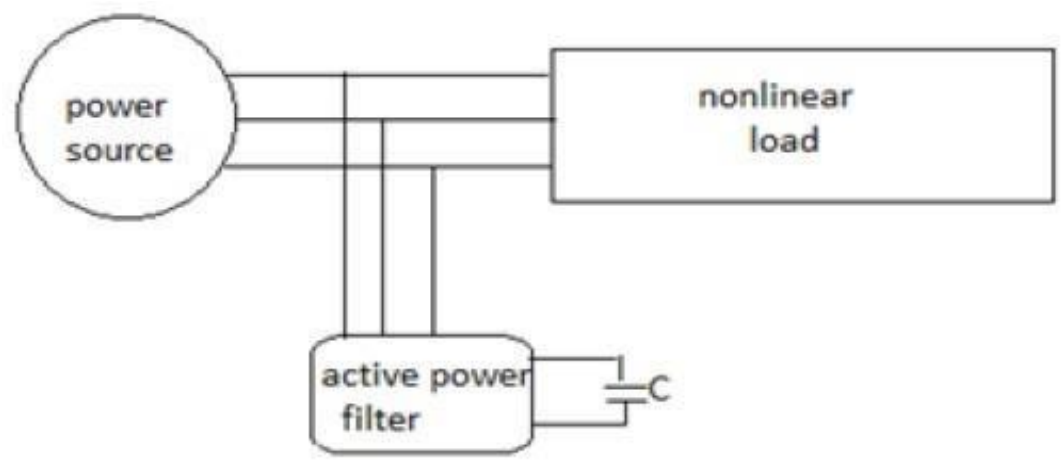

Figure 3 Block Diagram of active filters

The APF system is a complex system that has to be configured in a suitable way so that itfulfills the purpose of the application. The configuration is done in three steps; selection 
of the converter, topology and controller. The first step is to choose the convertertype, either Current Source Inverter (CSI) or Voltage Source Inverter (VSI), in a CSI, an inductor is used as the main energy storage device and a capacitor is used in the VSI case. The VSI is the most dominant and frequently implemented because it is less expensive and easier to control in comparison to the CSI. The second step is to determine the topology which can either be series, a shunt or hybrid connection. The final step is to select a controller and switching mode suitable for the selected topology.

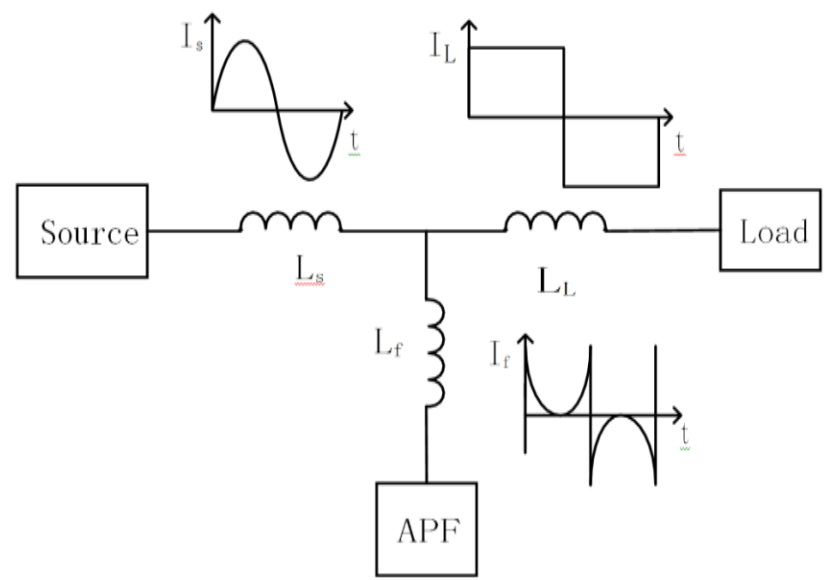

Figure 4 APF

\section{(i) Shunt APF}

The shunt APF was first introduced in [4] and has evolved to be used in commercial operation all over the world ever since. The shunt APF is one of the most popular topologies used for mitigating harmonics today [5]. The controller monitors the current consumed by the load $\left(\boldsymbol{I}_{L}\right)$ and then creates an compensation current reference $\left(\boldsymbol{I}_{a f^{*}}\right)$ that generates the compensation current $\left(I_{a f}\right)$ that goes back in to the system. The reference is used as an input to the power converter which then reproduces the inverse of the harmonics by switching in an certain pattern determined by the controller, see Fig.5.

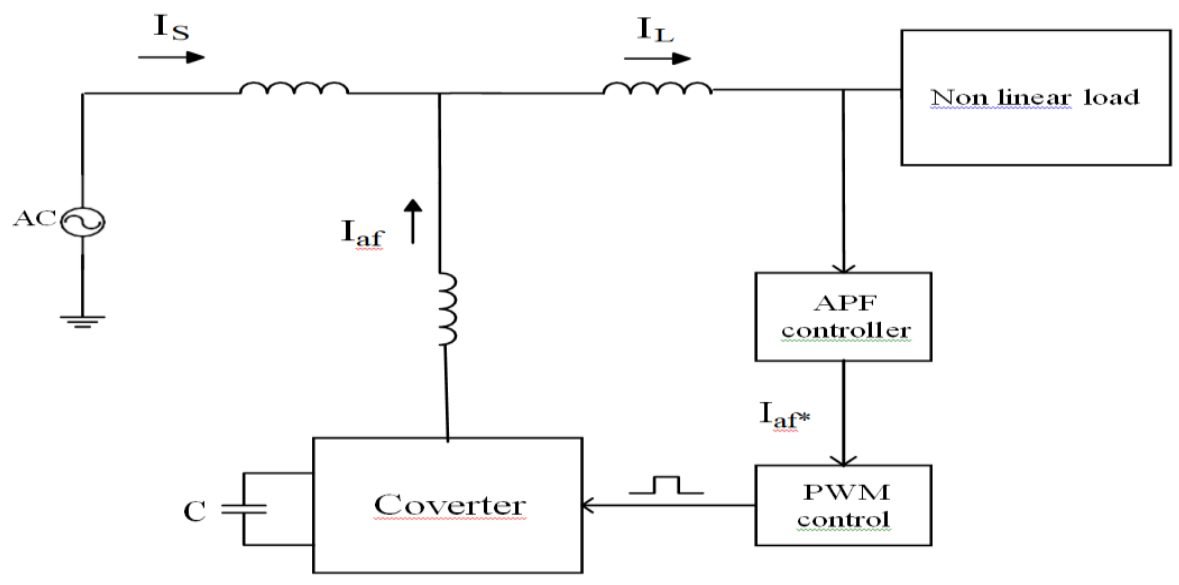

Figure 5 Shunt APF 


\section{(ii) Series $\mathrm{APF}$}

The reason being that the series APF uses no energy storage devicesuch as batteries and the rating of the series APF devise is smaller in comparison to the UPS.

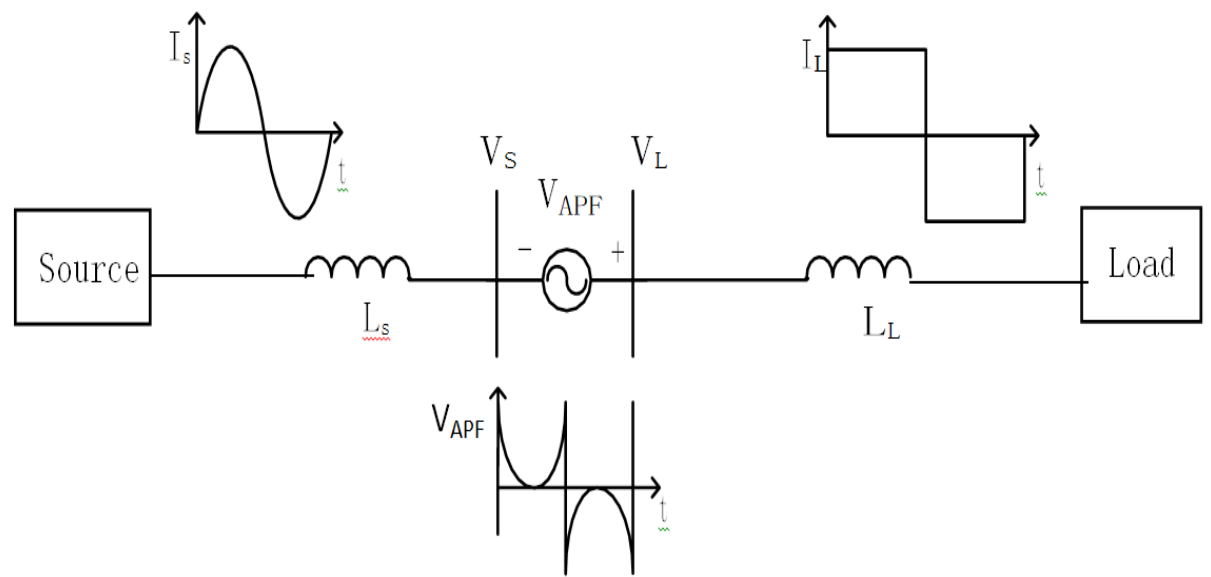

Figure 6 Series APF

\section{(iii) Hybrid APF}

A Hybrid APF is a combination of a shunt APF and a passive filter part and is shown in Fig.7.

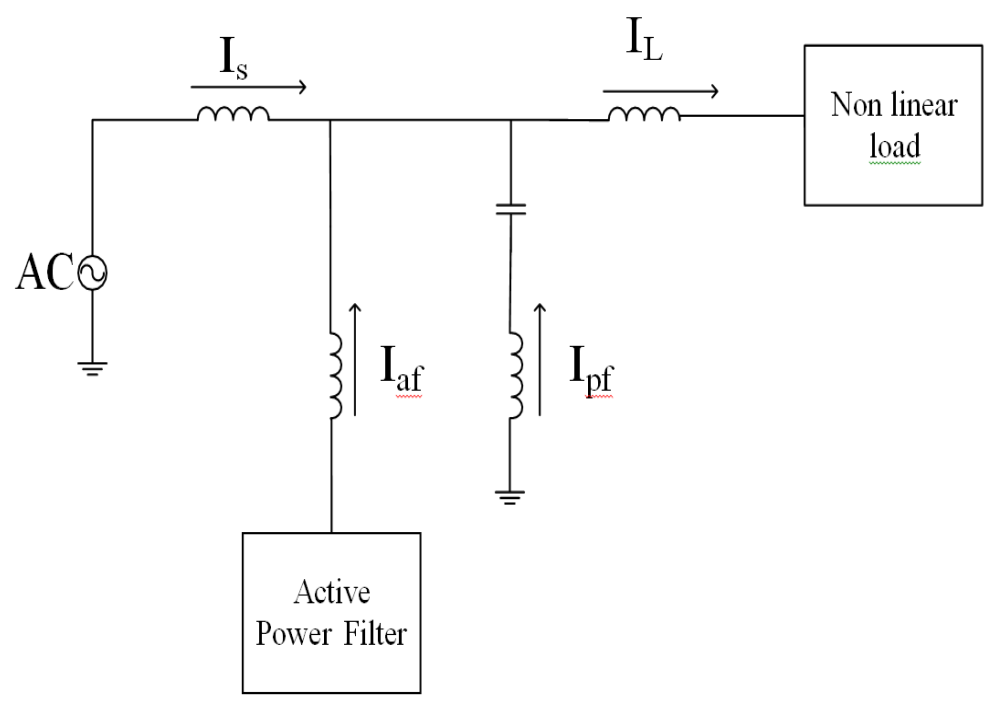

Figure 7 Hybrid APF 


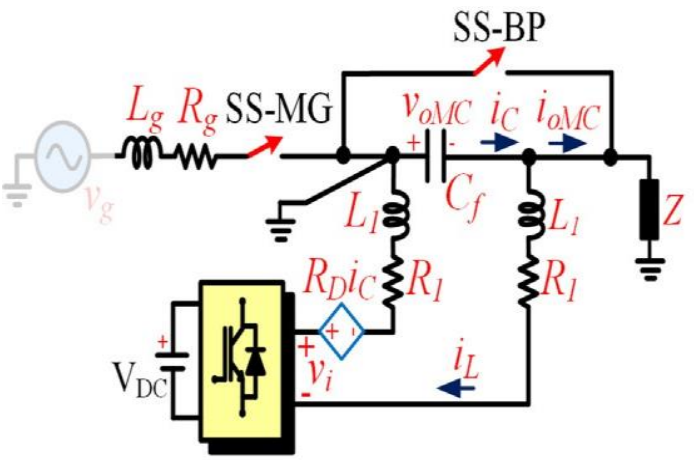

(a)

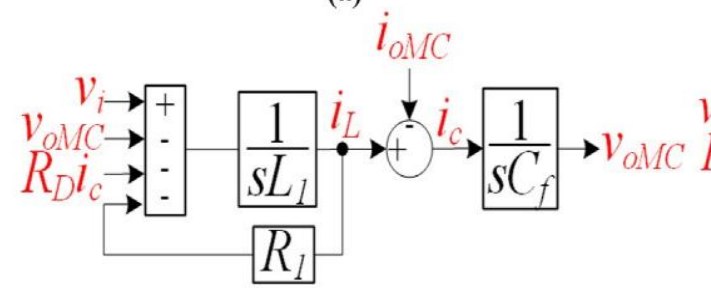

(c)

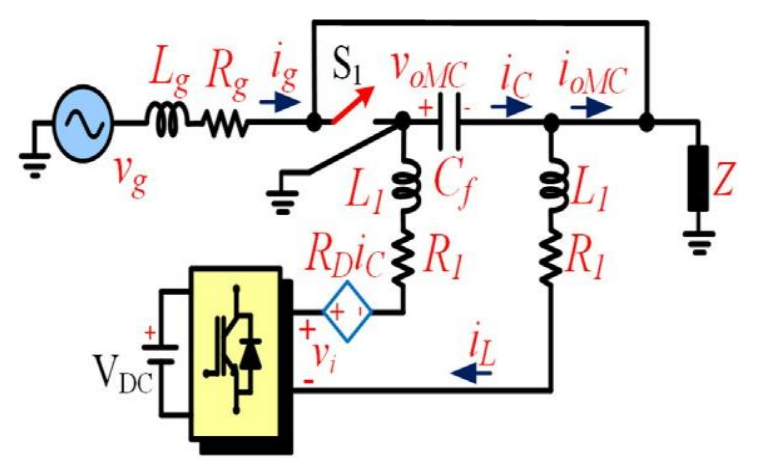

(b)

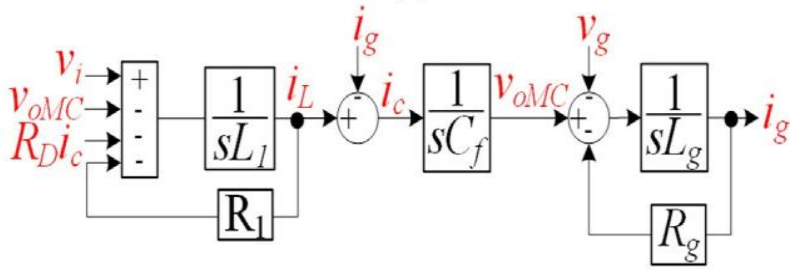

(d)

Figure 8 Single line diagram of multifunctional converter: (a) islanded mode (mode V); (b) grid-connected mode (mode IV); (c) block diagram of the LC filter in islanded; and (d) gridconnected mode.

\section{SIMULATION RESULTS}

Following figures describes how control is working when converter operate in different operating mode for linear and nonlinear load. Converter current follows reference current as is shown. The control error signal is approximately zero. Waveform of the load current is also shown. Sum of the inverter current and load current is grid current which form is also shown.
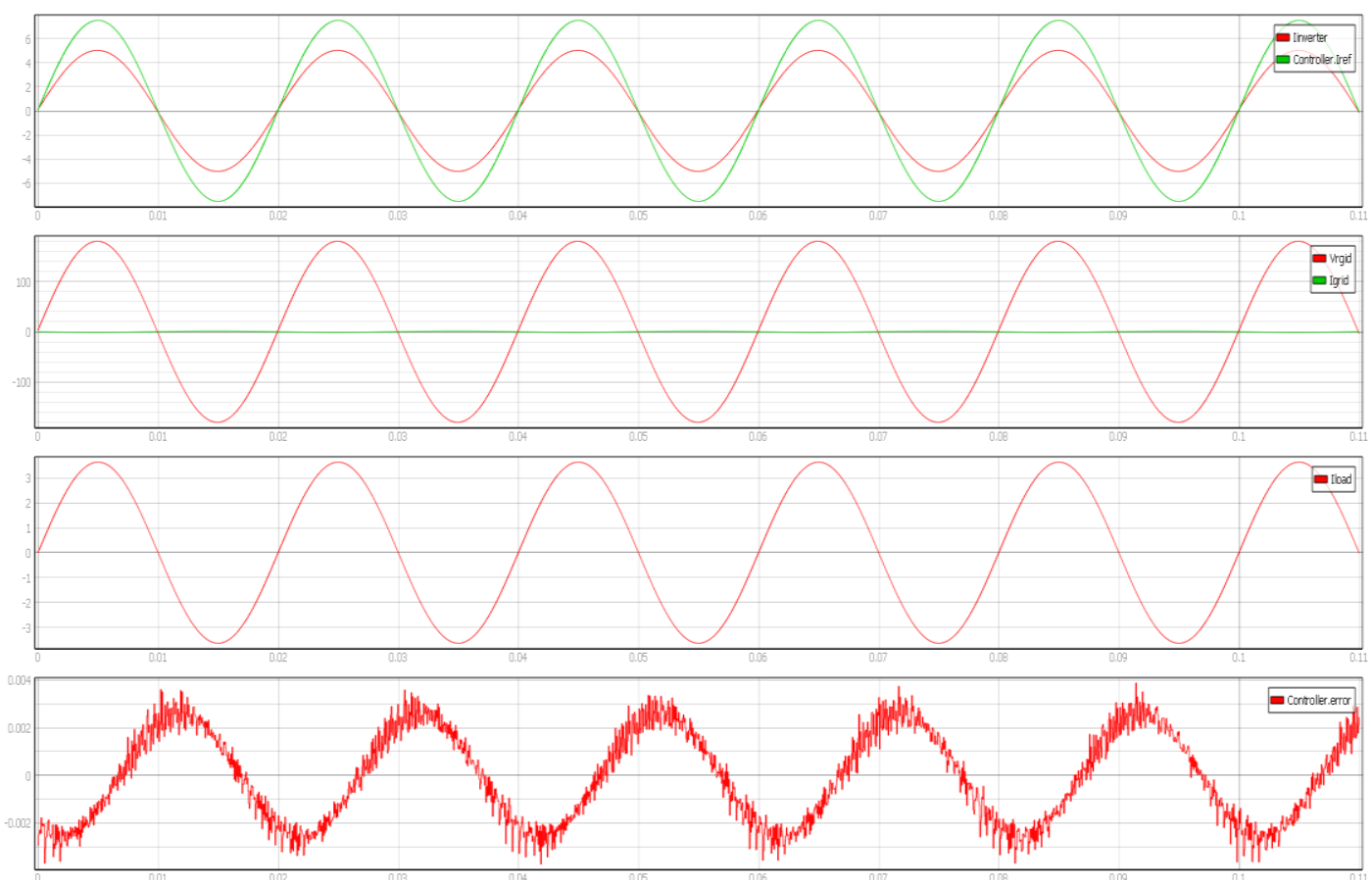

Figure 9 Active Power Injection for linear load. 

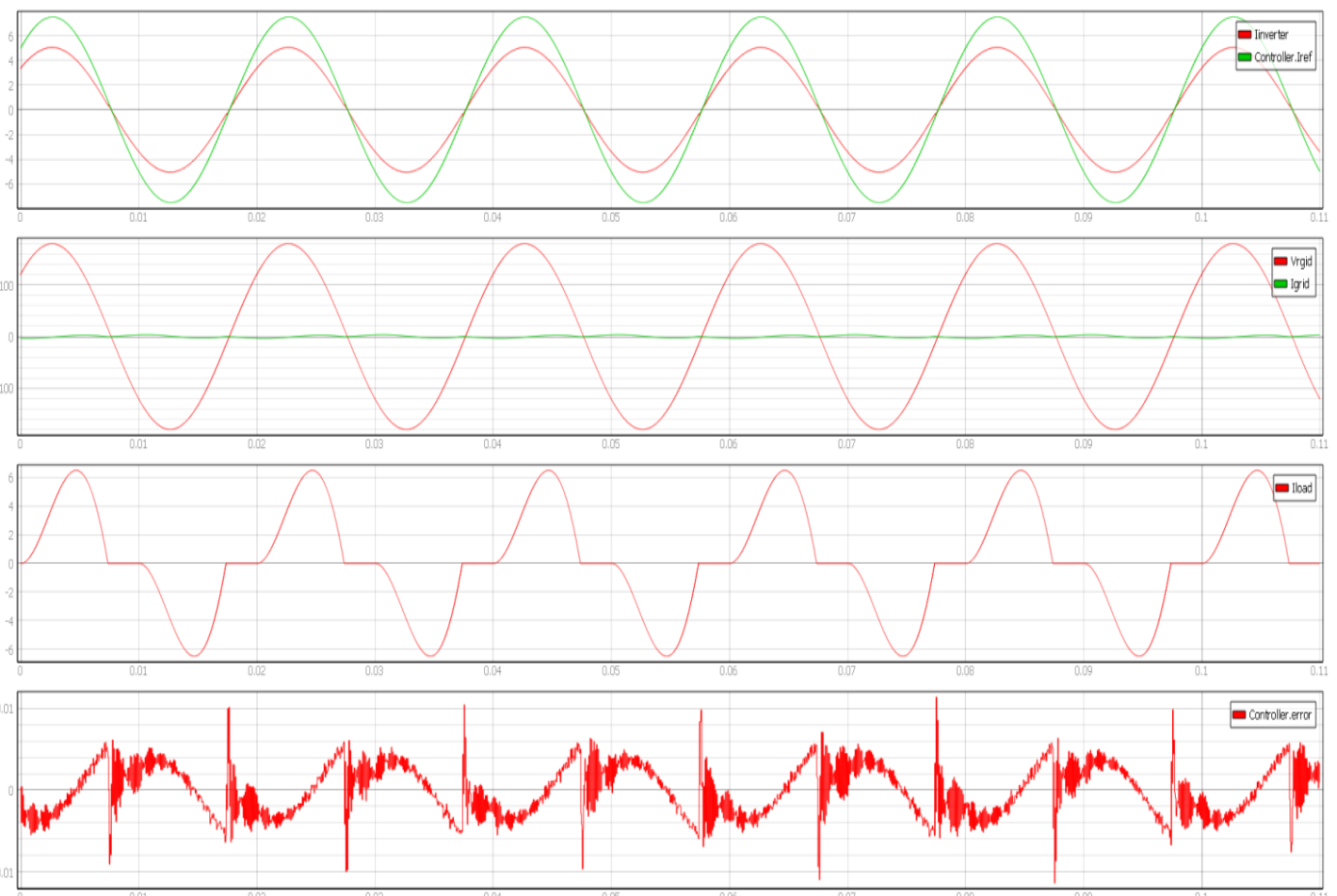

Figure 10 Active Power Injection for non-linear load.
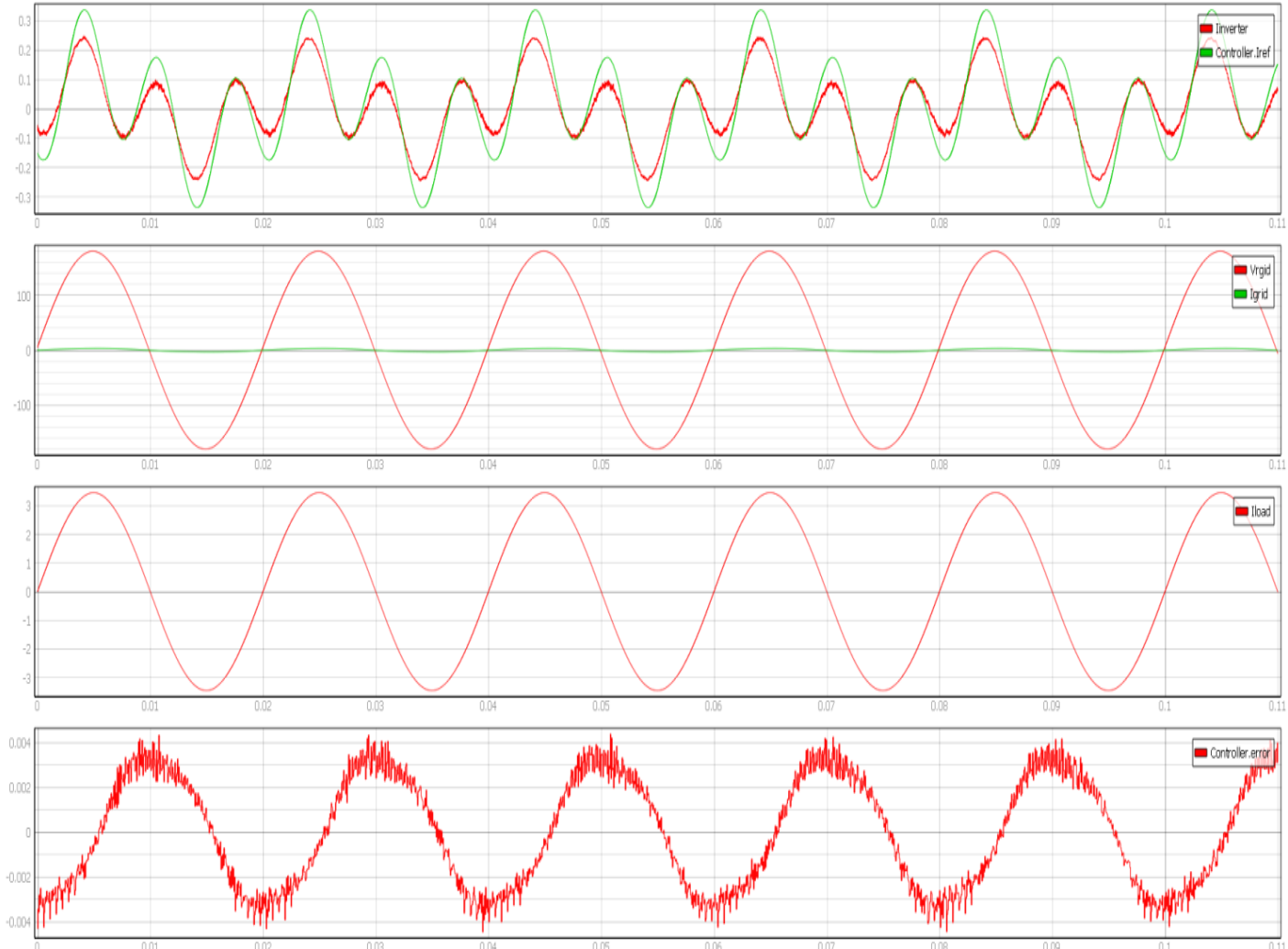

Figure 11 Active Power Compensation for linear load. 
Performance Analysis of Multi-functional Grid connected Converter Under different Operating Modes
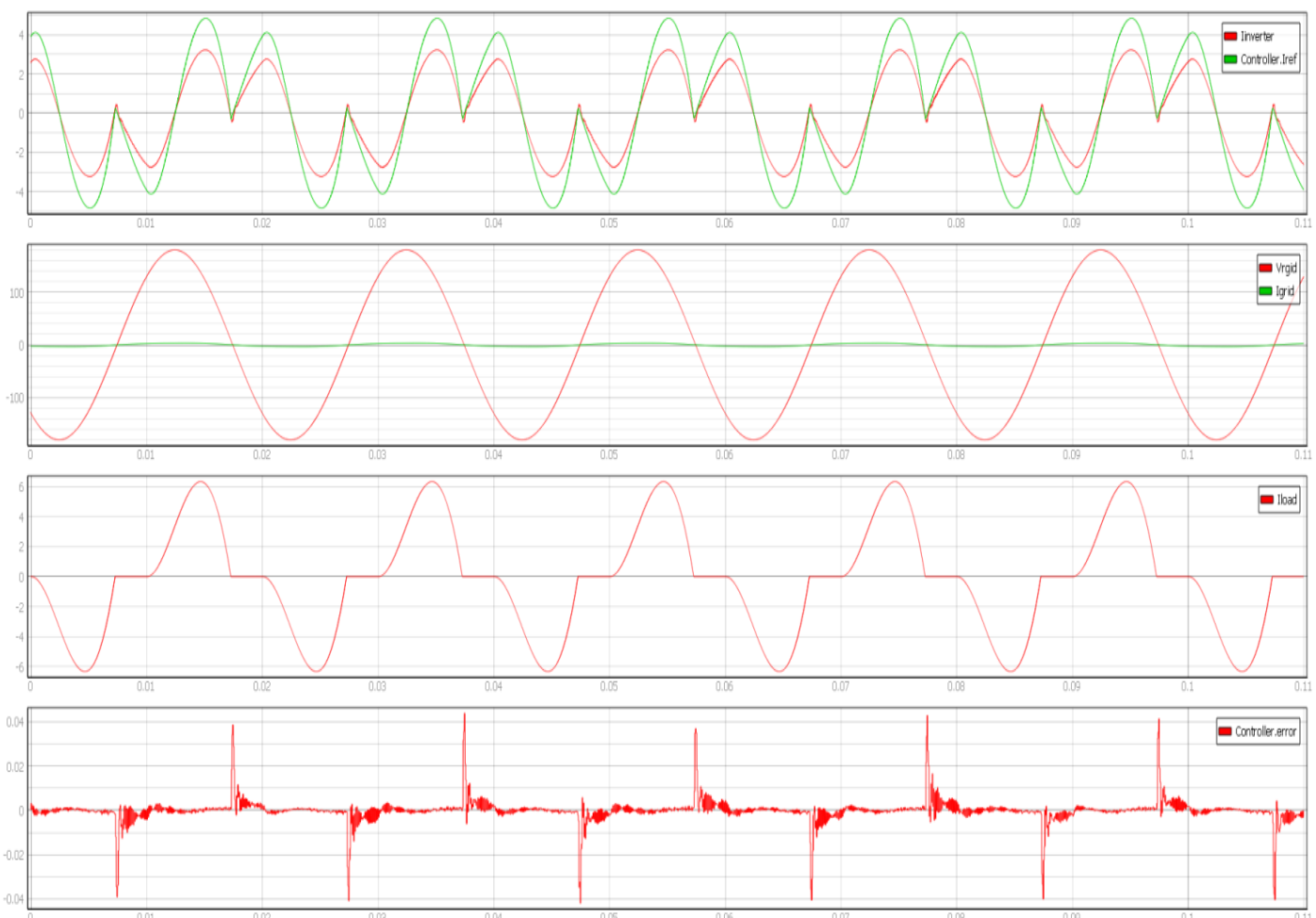

Figure 12 Active Power Compensation for non-linear load.
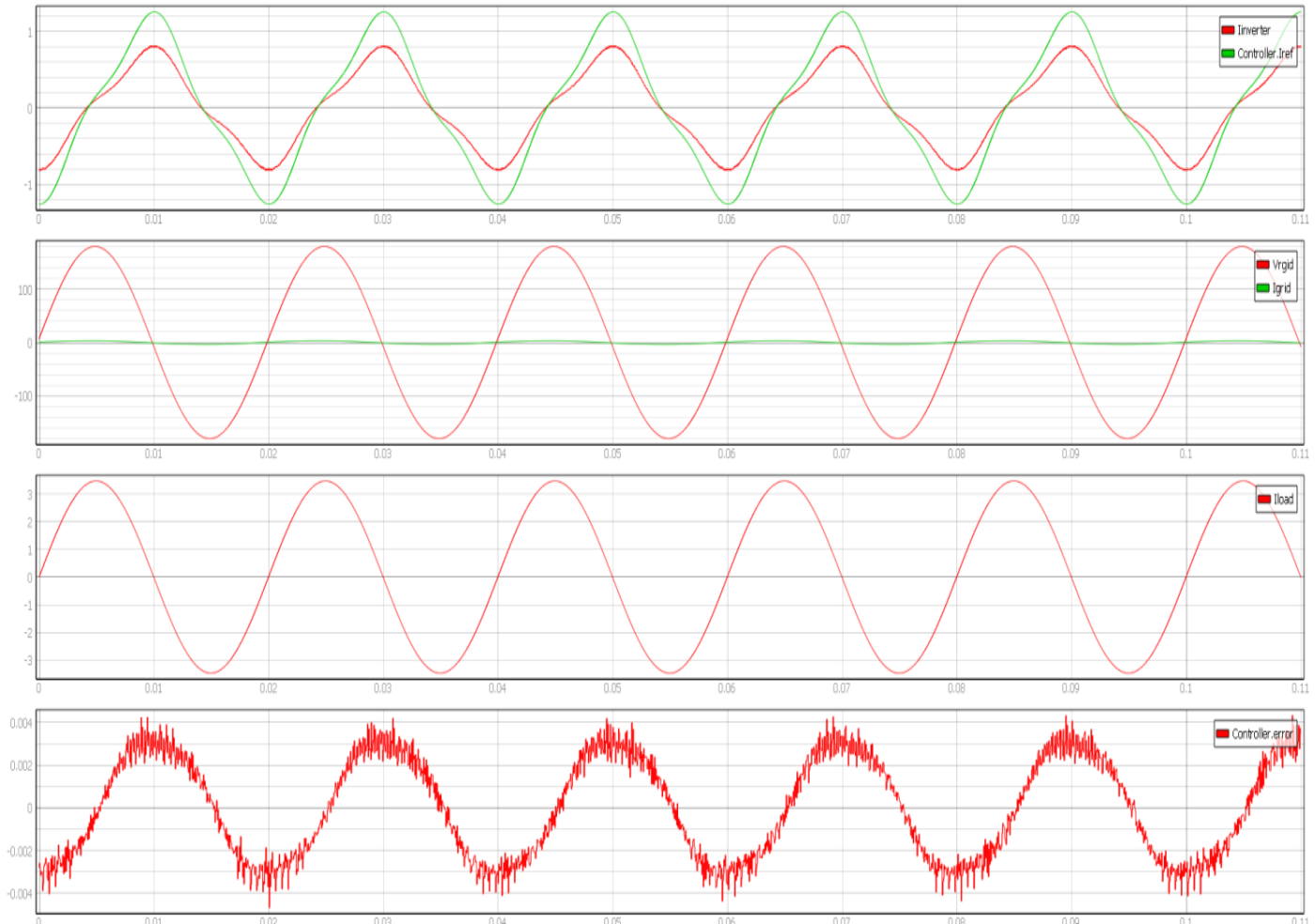

Figure 13 Reactive Power Compensation for linear load. 
Vinod Kumar Yadav, Rajnish Bhasker, Satyam Kumar Upadhyay
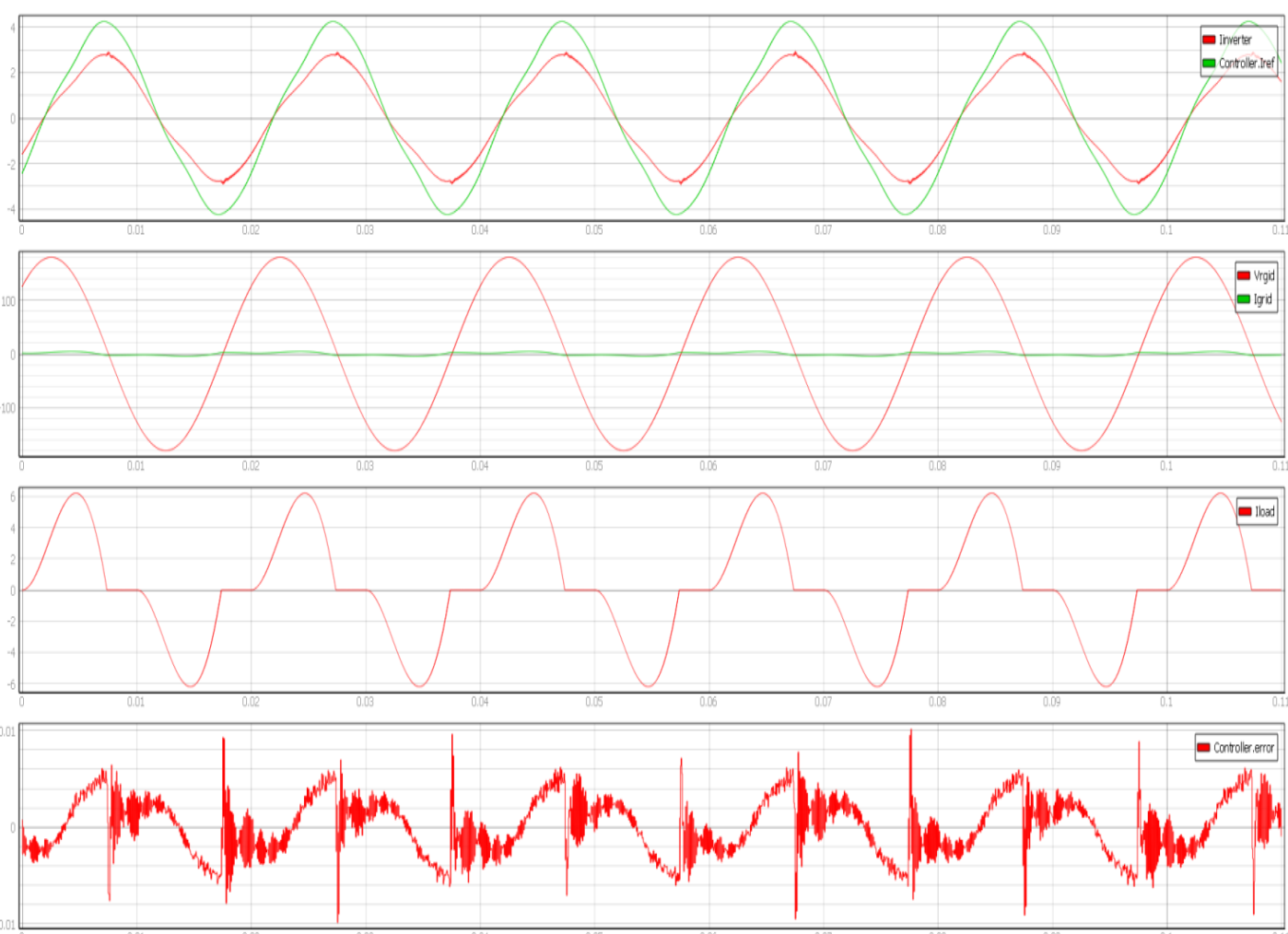

Figure 14 Reactive Power Compensation for non-linear load.
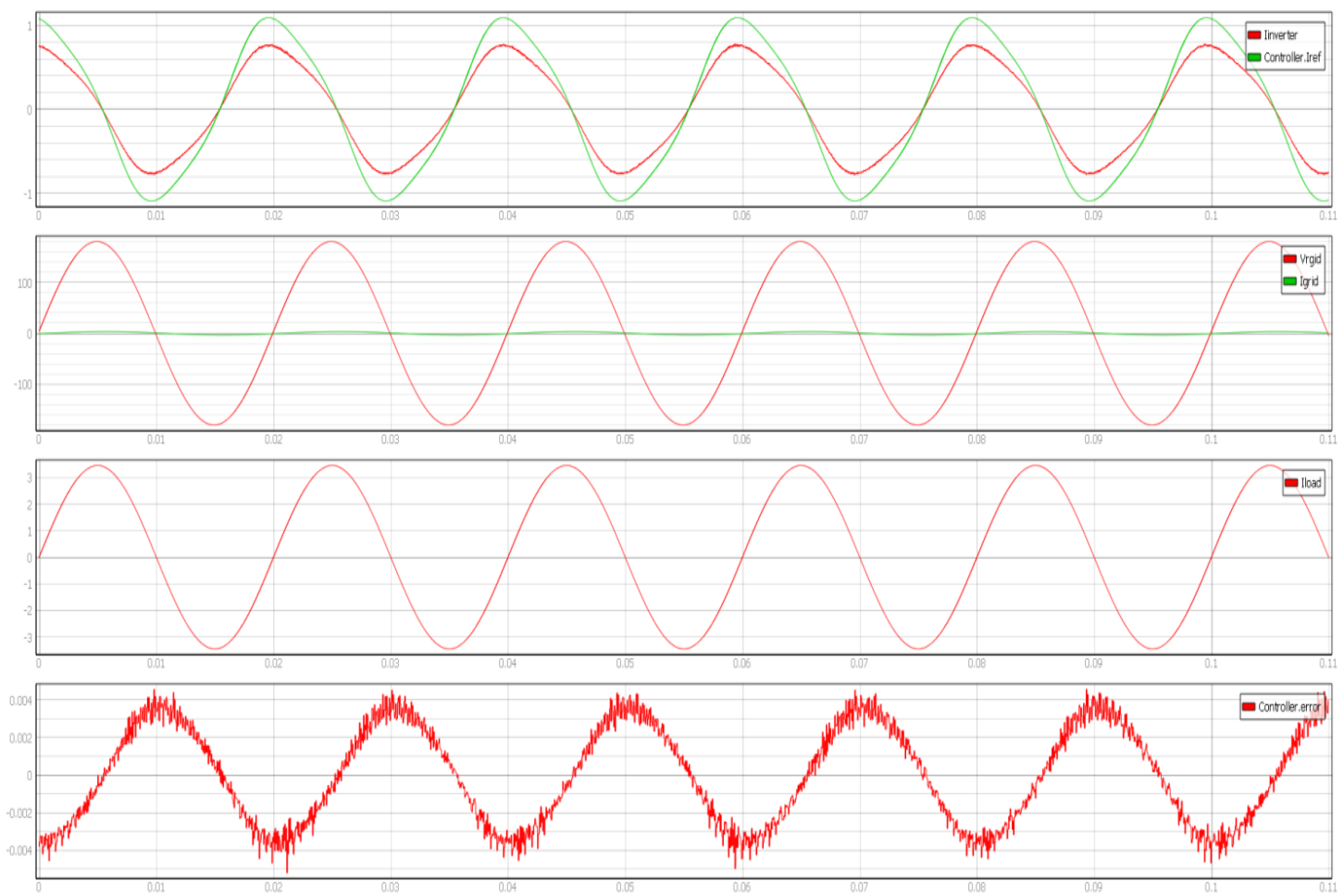

Figure 15 Harmonics Compensation for non-linear load. 
Performance Analysis of Multi-functional Grid connected Converter Under different Operating Modes
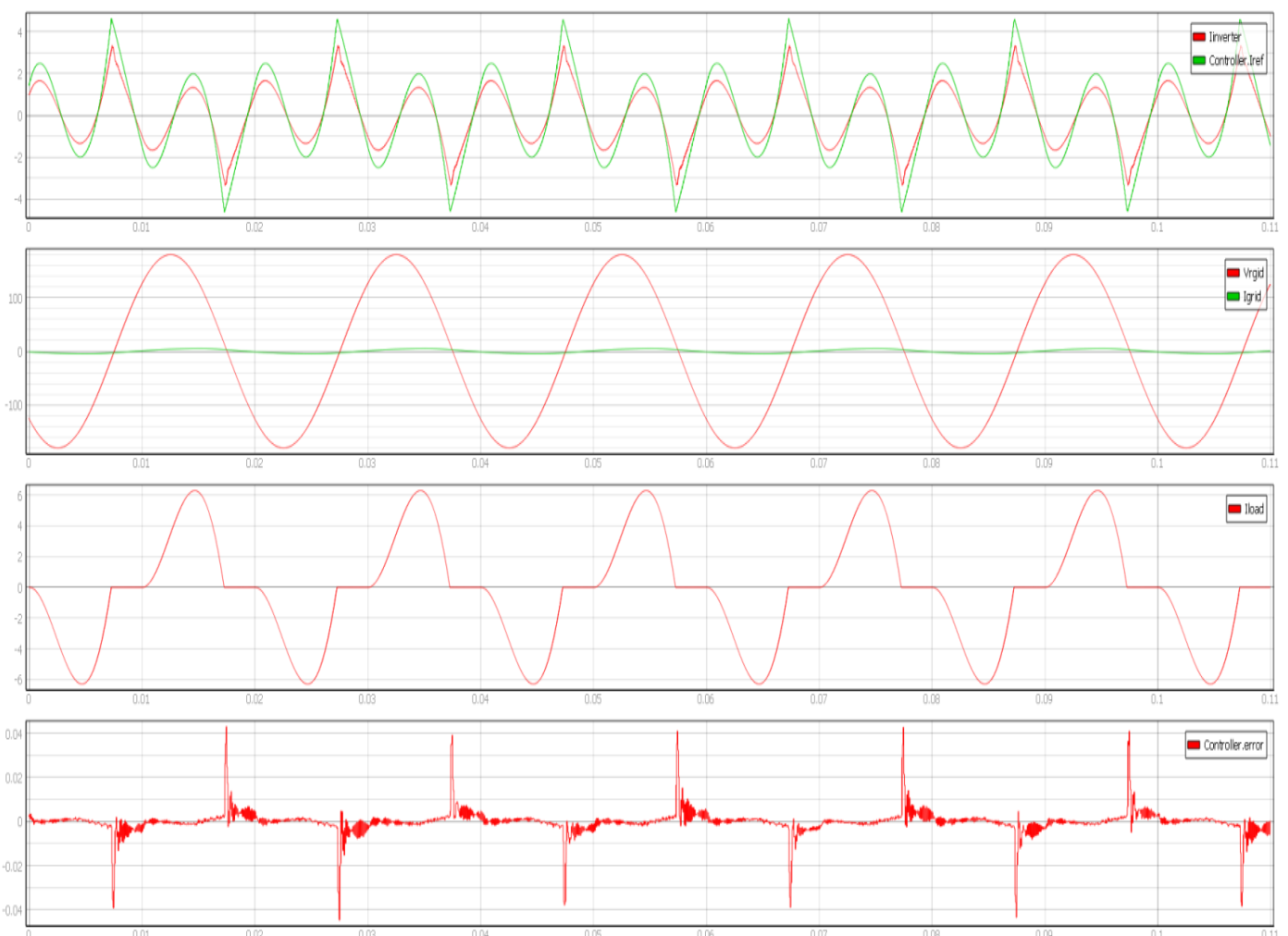

Figure 16 Harmonics Compensation for non-linear load.
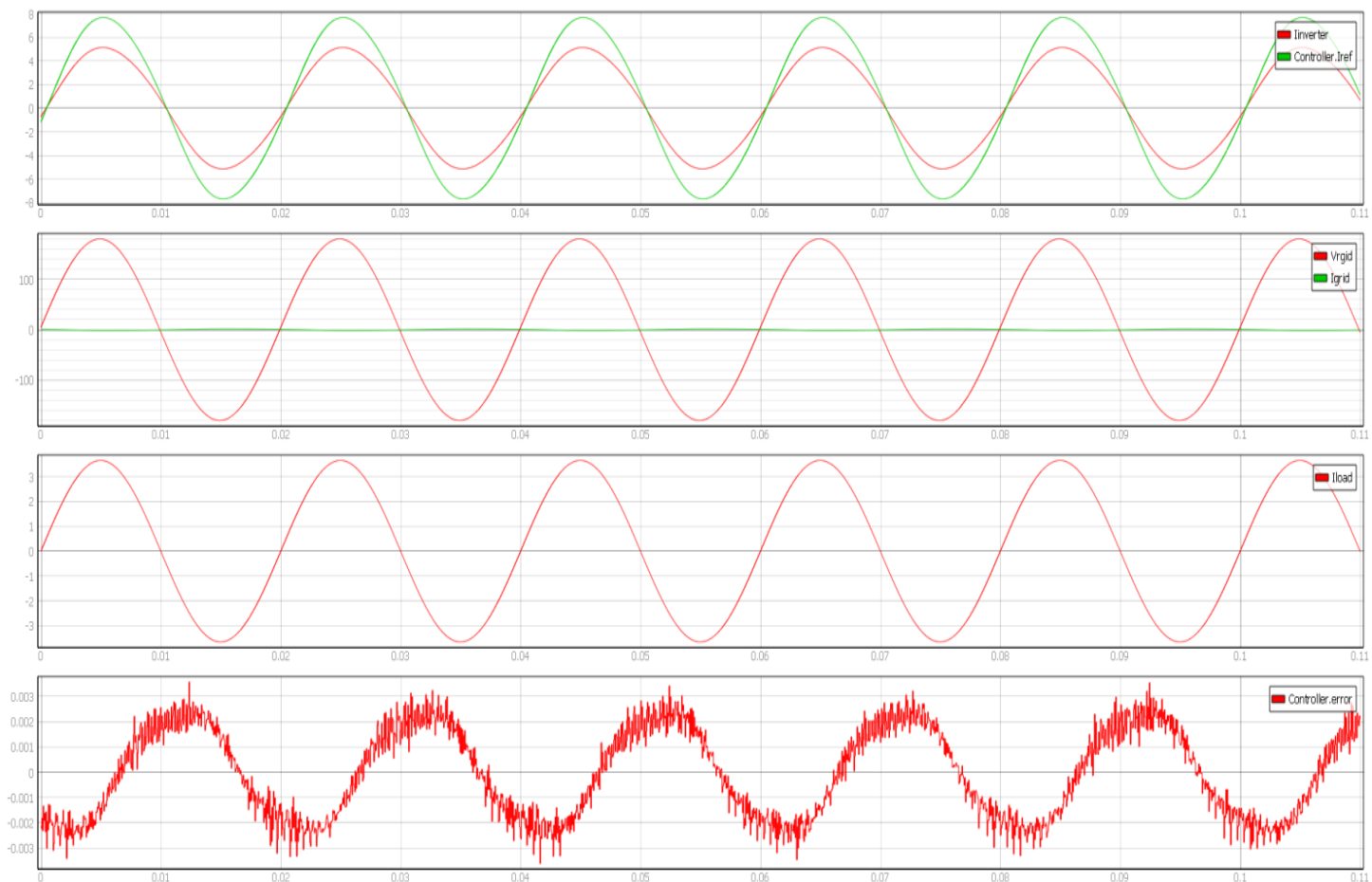

Figure 17 Active Power Injection \& Reactive Power Compensation for linear load 

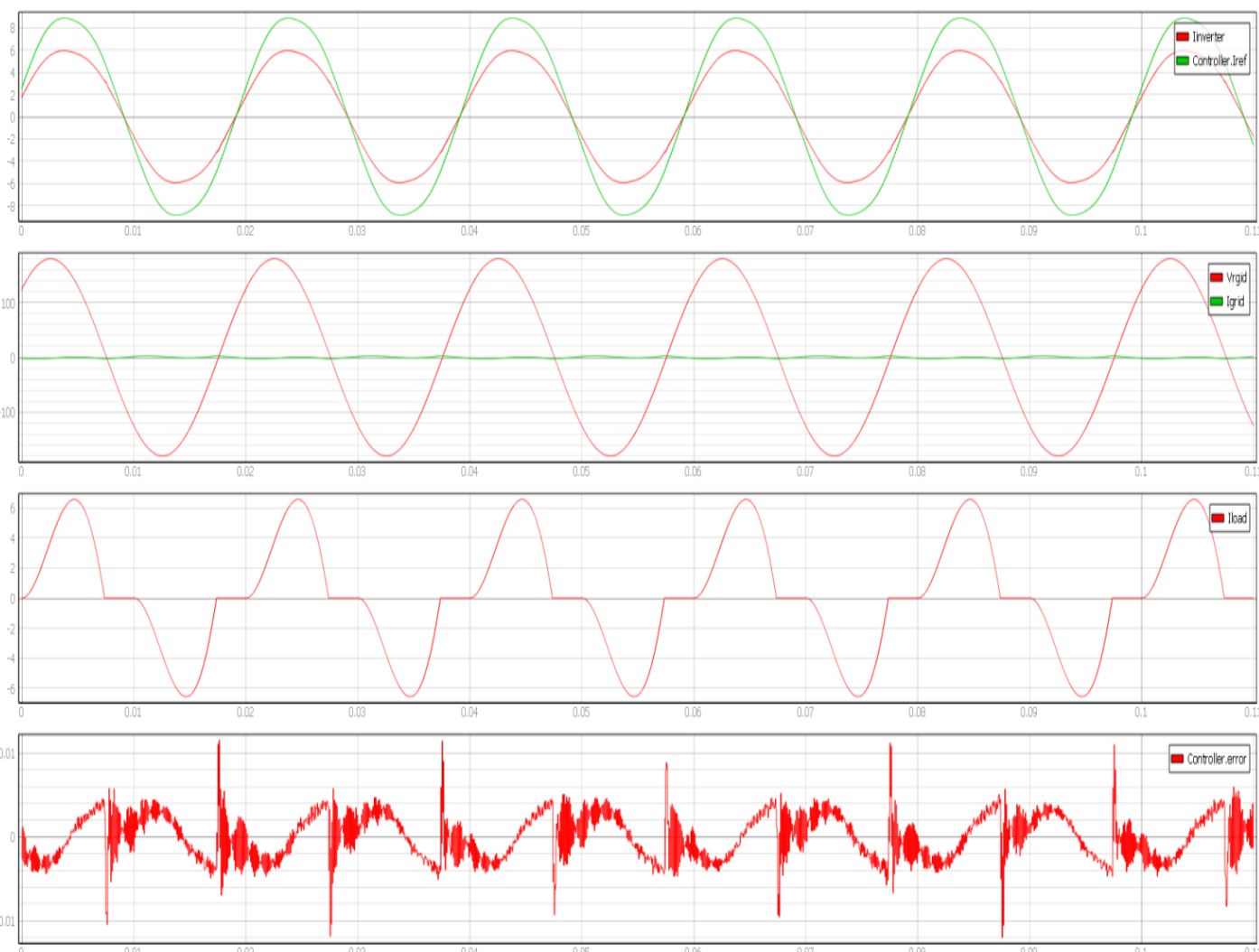

Figure 18 Active Power Injection \& Reactive Power Compensation for non-linear load.
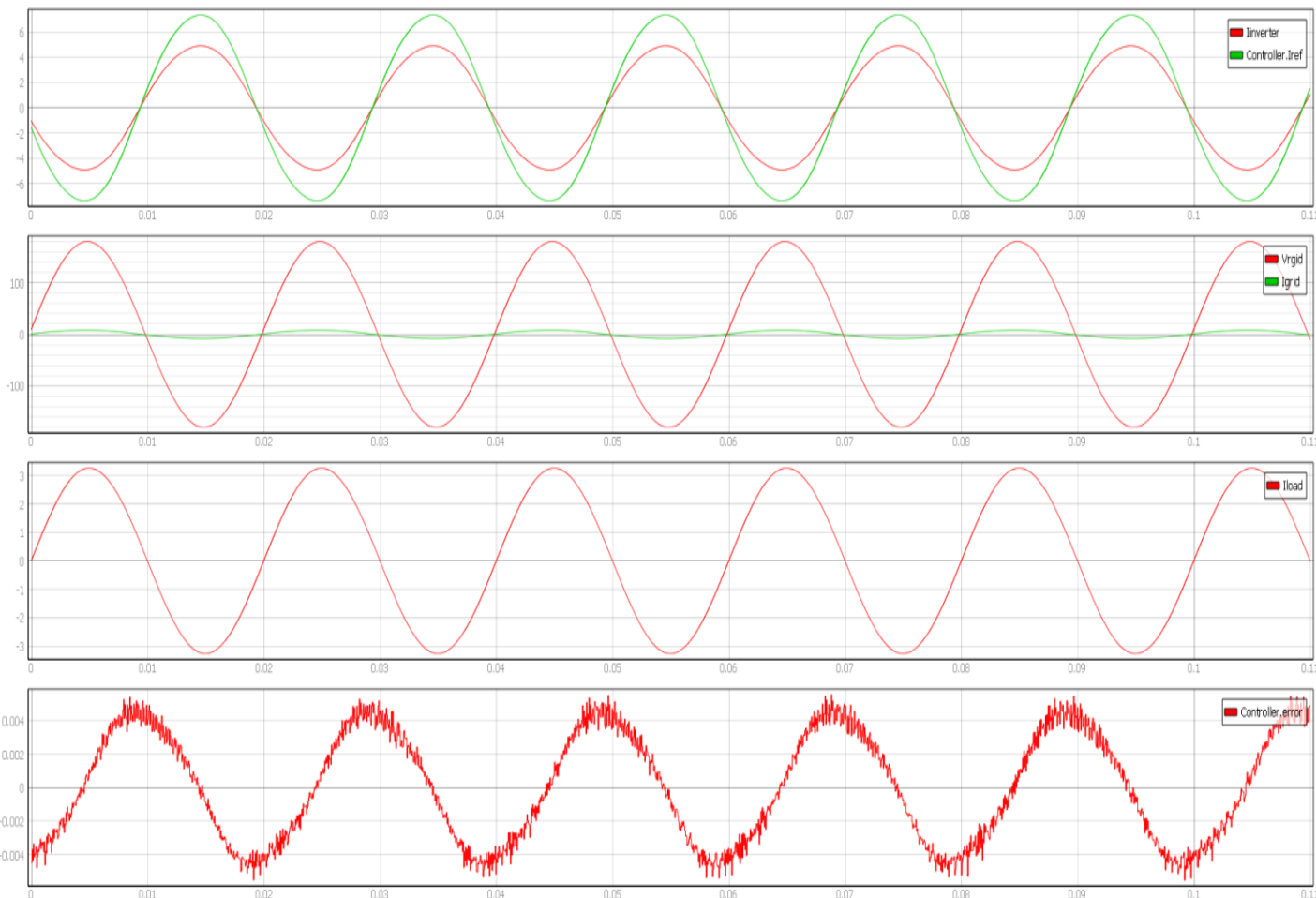

Figure 19 Active Power Consumption \& Reactive Power Compensation for linear load. 
Performance Analysis of Multi-functional Grid connected Converter Under different Operating Modes
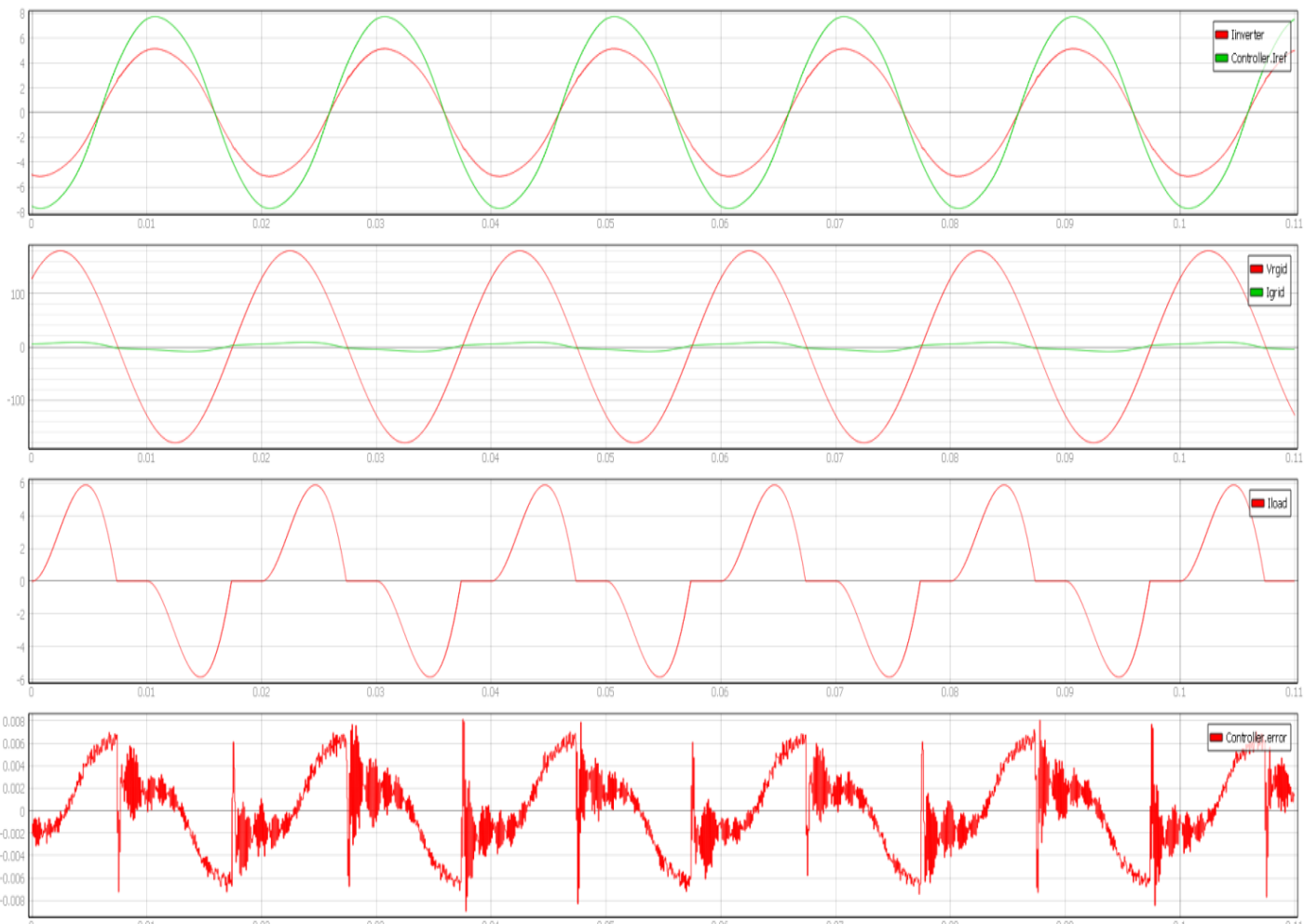

Figure 20 Active Power Consumption \& Reactive Power Compensation for non-linear load.
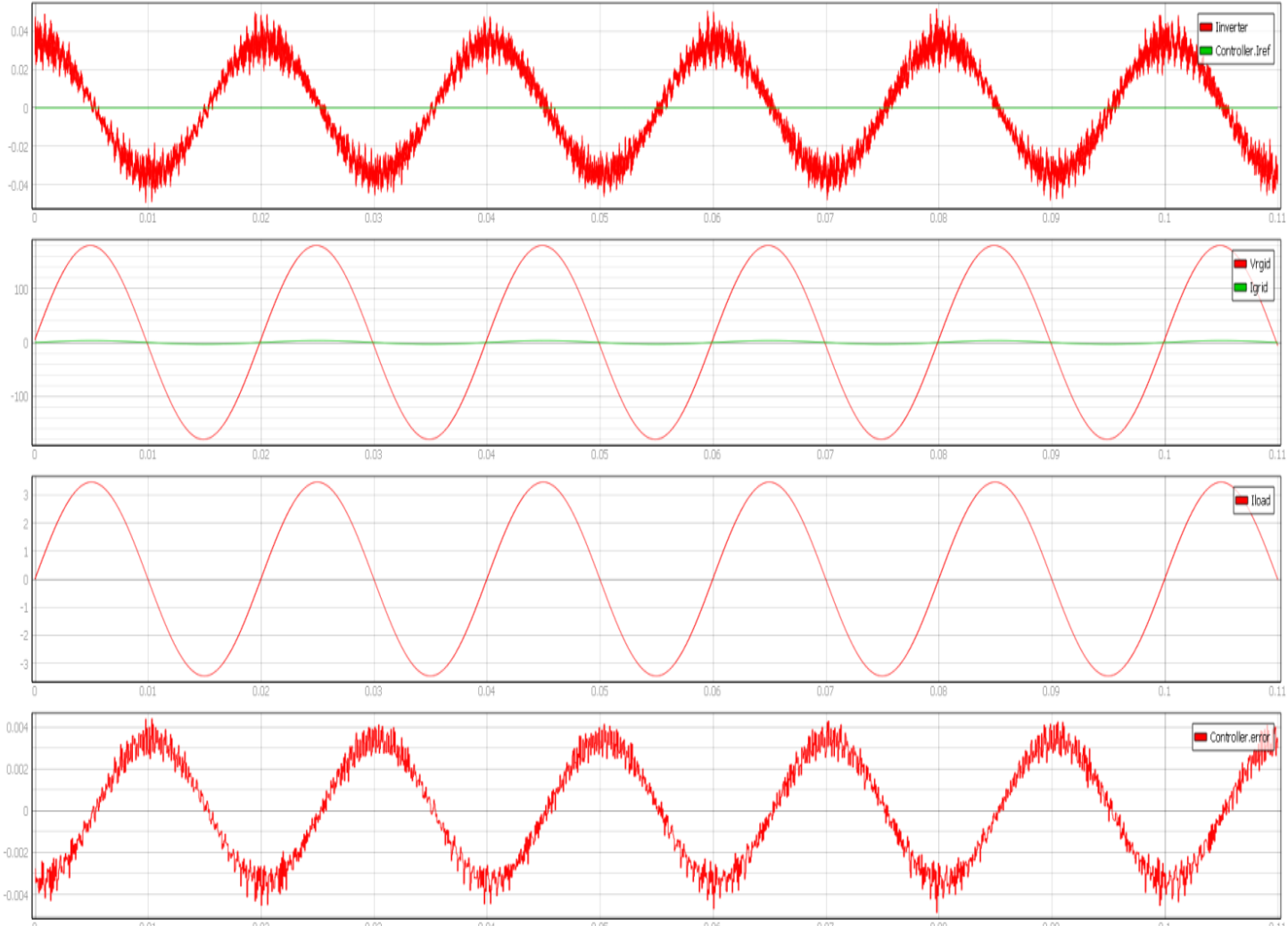

Figure 21 Standby Mode for linear load. 

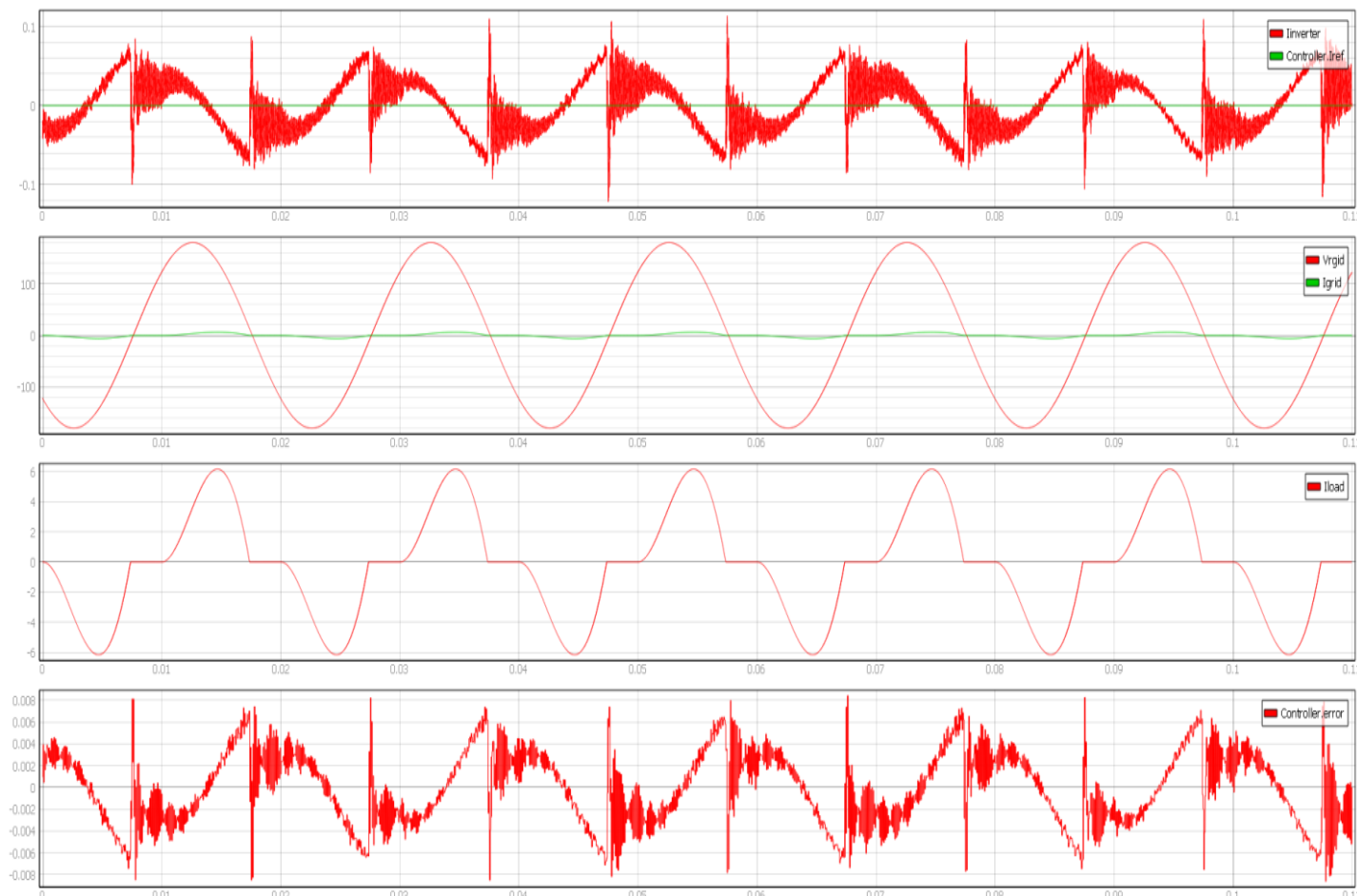

Figure 22 Standby Mode for non-linear load.

The control algorithm for the single-phase single-leg grid connected converter is implemented and validated in Typhoon HIL system. The converter and power grid were built inside Schematic Editor. Then, the system was compiled inside the real timesimulator "Typhoon HIL". Typhoon HIL allows precise benchmarking of real-time controllers, with specific sampling for specific control blocks. The control of the converter was implemented in the Virtual HIL402, inside the Typhoon HIL402 software. The CPT theory was modeled inside the schematic editor along with the current controllers. A sampling frequency of $60 \mathrm{kHz}$ is used to discrete the signals. The test is implemented for various operating modes.

\section{CONCLUSION}

The proposed system is implemented in Typhoon HIL and the results obtained are presented in this report. Battery is the renewable energy source used in the system for providing active power to the load. The simulation results show that CPT can be used for design and control of filters and compensators. CPT is a relatively simple control method when compared to the existing strategies since there is no transformation involved as in d-q method or PQ theory where Park's transformation or Clarke's transformation is to be done. The instantaneous voltage and currents are only required for this current decomposition technique. Both active and reactive power compensation can be easily achieved. Control and maintenance of DC-Link are also possible by this method which can be seen from the above results where the DC-link voltage approaches the reference DC-link voltage after the CPT compensation starts at $4 \mathrm{sec}$. It can be seen that when reactive power delivery is done, the current and voltage are out of phase. Hence, CPT control strategy provides easy control of VSC for active and reactive power delivery as well as for reducing the harmonics present in the grid current and voltage due to non-linear load. When the power output is low, it can be seen the battery is supplying power and also is responsible for maintaining the dc-link capacitor voltage constant. 


\section{REFERENCES}

[1] Jinwei He, Yun Wei Li, Frede Blaabjerg and Xiongfei Wang, Active Harmonic Filtering Using Current-Controlled, Grid-Connected DG Units with Closed-Loop Power Control, IEEE Transactions on Power Electronics.vol.29, no 2, p 642-653, February.2014.

[2] Edris Pouresmaeil, Carlos Miguel-Espinar, Miquel Massot-Campos, Daniel MontesinosMiracle and Oriol Gomis-Bellmunt, A control Technique for Integration of DG Units to the Electrical Networks, IEEE Transactions on Industrial Electronics, vol. 60, no 7, p 2881- 2893, July.2013.

[3] Si-Hun Jo, Seo Eun Son and Jung-Wook Park, On improving Distortion Power Quality Index in Distributed Power Grids, IEEE Transactions on Smart Grid., vol. 4, no 1, p 586-595, March.2013.

[4] Prakash K. Ray, Soumya R. Mohanty, and Nand Kishor, Classification of Power Quality Disturbances Due to Environmental Characteristics in Distributed Generation System, IEEE Transactions on Sustainable energy., vol. 4, no 2, p 302-313, April 2013.

[5] Rafael Amral Shayani and Macro Aurelio Goncalves de Oliveira, Photovoltaic Generation Penetration Limits in Radial Distribution Systems, IEEE Transactions on Power Systems.vol.26, no. 3, p 1625-1631, August.2011.

[6] T. Zhou and B. François, Energy management and power control of a hybrid active wind generator for distributed power generation and grid integration, IEEE Trans. Ind. Electron., vol. 58, no. 1, p. 95-104, Jan. 2011.

[7] M Singh, V. Khadkikar, A. Chandra, and R. K. Varma, Grid interconnection of renewable energy sources at the distribution level with power quality improvement features, IEEE Trans. Power Del., vol. 26, no. 1, p. 307-315, Jan. 2011.

[8] M. F. Akorede, H. Hizam, and E. Pouresmaeil, Distributed energy resources and benefits to the environment, Renewable Sustainable Energy Rev., vol. 14, no. 2, p. 724-734, Feb. 2010.

[9] C. Mozina, Impact of green power distributed generation, IEEE Ind. Appl. Mag., vol. 16, no. 4, p. 55-62, Jun. 2010.

[10] E. Pouresmaeil, D. Montesinos-Miracle, O. Gomis-Bellmunt, and J. Bergas-Jané, A multiobjective control strategy for grid connection of DG (distributed generation) resources, Energy, vol. 35, no. 12, p. 5022-5030, Dec. 2010.

[11] Milka Salo and Heikki Tuusa, A Novel open-Loop Control Method for a Current Source Active Power Filter, IEEE Transactions on Industrial Electronics, vol. 50, no 2, p 313-321, April.2003.

[12] Giovani Guarienti Pozzebon, Amilcar Flamarion Querubini Goncalves, Guido Gomez Pena, Nilton Eufrazio Martino Mocambique and Ricardo Quadros Machado, Operation of a ThreePhase Power Converter Connected to a Distribution System, IEEE Transactions on Industrial Electronics, vol. 60, no 5, p 1810-1818, May.2013.

[13] V. Hima Leela and S Thai Subha, Control of Power Converter for Power Quality Improvement in a Grid Connected PV system, ICCPCT, IEEE, 2013, p. 26-30.

[14] Tenti P, Paredes HK, Mattavelli P. Conservative power theory, a framework to approach control and accountability issues in smart microgrids. IEEE Trans Power Electron. 2011; 26:66473 